\title{
GÊNESE DA RELAÇÃO DE PARCERIA ENTRE INCRA E MOVIMENTOS SOCIAIS COMO MODELO PARA IMPLEMENTAÇÃO DE POLÍTICAS DE REFORMA AGRÁRIA ${ }^{1}$
}

\author{
Camila Penna
}

é professora do Departamento de Sociologia da Universidade Federal do Rio Grande do Sul

(UFRGS).Porto Alegre, RS, Brasil. E-mail: <camilapennac@gmail.com>

Orcid: 0000-0001-5579-1653

http://dx.doi.org/10.1590/0102-115148/105

\section{Introdução}

A implementação das políticas de reforma agrária no Brasil é atualmente caracterizada por um formato "associativo", que implica uma parceria entre movimentos de luta pela reforma agrária e o Instituto Nacional de Colonização e Reforma Agrária (Incra). Nessa parceria os movimentos têm o papel de organizar e apresentar a demanda (de beneficiários e de terras), e o Estado tem o papel de levar a cabo os processos administrativos de desapropriação ou aquisição de propriedades, criar projetos de assentamento e cadastro dos beneficiários no Programa Nacional de Reforma Agrária (PNRA), além de autorizar a liberação de crédito para fomento agrícola. Os papéis atribuídos a cada ator nessa parceria, que envolve uma dimensão de pressão e outra de colaboração institucional, são constantemente disputados e

\footnotetext{
1 Agradeço a Marcelo Kunrath Silva, Luciana Tatagiba e Rebecca Abers pelos comentários às versões anteriores deste artigo, e aos grupos de pesquisa Sociologia Não-Exemplar, Repensando as Relações entre Sociedade e Estado (Resocie) e Associativismo, Contestação e Engajamento (GPACE) pelos diálogos e trocas que contribuíram para sua formulação.
} 
renegociados. Todavia, não é exagero dizer que a implementação do PNRA seria inviável sem a colaboração dos movimentos sociais (Penna, 2015; Wolford, 2010).

Parte das regras e dos procedimentos que orientam essa parceria está cristalizada em legislação e parte é fruto de consenso tácito construído ao longo do tempo. Ambas orientam práticas e rotinas burocráticas. As normas e formas de agir que caracterizam atualmente a atuação do Incra e dos movimentos sociais na implementação da política de reforma agrária são resultado de um longo processo histórico de mudanças, que tem origem ainda no período militar e segue em constante reformulação. A compreensão de como o atual formato associativo foi conformado requer um olhar para o passado e para as diferentes maneiras pelas quais o Incra se relacionou com seus beneficiários (organizados ou não em movimentos sociais). Desde o período da redemocratização até o momento atual, cada situação de mudança institucional resulta de um agenciamento ou assemblage diferente (Deleuze e Guattari, 1994; Latour, 2005; Berk, Galvan e Hattan, 2013). Ou seja, a composição que emerge das relações entre os diversos atores envolvidos no processo de implementação vai sofrendo alterações, assim como as práticas e posições desses atores.

Neste artigo busco traçar a gênese da atual relação de parceria entre Incra e movimentos sociais olhando para os agen-

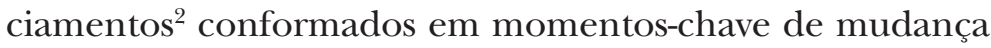
política: o retorno à democracia, o Massacre de Eldorado dos Carajás ${ }^{3}$ e seus efeitos para a organização dos movimentos

2 O termo em francês agencement, que aparece na obra de Deleuze e Guattari, Mil platôs: capitalismo e esquizofrenia (1994), tem sido traduzido para o inglês como assemblage e para o português como "agenciamento". Neste artigo optei por utilizar o termo agenciamento, que aparece na tradução para o português da obra mencionada.

3 Assassinato de dezenove trabalhadores rurais, resultante da ação da polícia militar do Pará para desobstruir uma estrada bloqueada pelo Movimento Sem Terra (MST), que reivindicava a desapropriação de uma propriedade no município de Eldorado dos Carajás. 
sociais, e a transição do governo de Fernando Henrique Cardoso (FHC) para o de Lula. A discussão a seguir se baseia em pesquisa etnográfica realizada na Superintendência Regional do Incra de Marabá, no sul do Pará, entre outubro de 2011 e junho de 2012. A região é emblemática pelo histórico de conflito relacionado à posse da terra e pela forte organização e atuação dos principais movimentos de luta pela reforma agrária. A investigação envolveu observação participante de diferentes situações do cotidiano de trabalho da regional, entrevistas semiestruturadas e informais com servidores do órgão e consulta ao arquivo local.

O Incra é a autarquia federal responsável por implementar a política fundiária nacional, o que engloba, além do PNRA, a regularização fundiária e diferentes políticas de crédito e de fomento à produção agrícola. Durante o regime militar o Incra teve papel significativo no projeto de "colonização" da Amazônia, o que ainda marca a atuação do órgão na região Norte. A implementação de políticas de reforma agrária não é uniforme em todo o Brasil e varia conforme a configuração fundiária, o perfil agropecuário e a forma de organização e de atuação dos movimentos em cada Estado. Pode-se dizer que a cooperação com os movimentos é determinante para a atuação do Incra na grande maioria dos Estados, inclusive no nível federal. Contudo, o formato que toma essa cooperação é uma questão empírica e pode variar de acordo com o tempo e com o espaço estudado. Apresento a seguir uma interpretação do processo de mudança institucional pelo qual passou o Incra de Marabá nas últimas décadas, a partir da noção de agenciamento. Esse conceito, que engendra ao mesmo tempo um giro ontológico, teórico e metodológico, permite vislumbrar o aspecto dinâmico de agregação de diferentes elementos e atores em contextos-chave que levaram à criação de novos arranjos para a implementação de políticas. Argumento que interpretar mudança institucional a partir do conceito 
analítico "agenciamento" pode contribuir para uma visão mais abrangente das conexões entre macroprocessos, práticas dos atores para solucionar problemas específicos e implicações dessas práticas para o processo de mudança política.

A primeira parte do artigo retoma a discussão teórica sobre mudança institucional e contrapõe algumas abordagens influenciadas pelo pragmatismo e pelo pós-estruturalismo na ciência política e na sociologia. O objetivo é apresentar o debate por meio de conceitos e categorias analíticas que serão trabalhados na parte empírica. A seguir discuto os três momentos-chave e analiso como cada agenciamento implicou o surgimento de soluções e de projetos criativos que levaram a mudanças no processo de implementação, na relação entre Estado e movimentos e no formato da política. Ao final, apresento as principais conclusões e faço um balanço de como a literatura trabalhada ajuda a compreender as mudanças que levaram à construção do formato atual de implementação de políticas públicas pelo Incra.

\section{Olhando para a mudança institucional}

O tema da mudança política, mais especificamente da mudança institucional, tem recebido atenção crescente nas ciências sociais nos últimos anos. Abordagens mais influenciadas pelo estruturalismo, dominantes nos anos 1980, têm dado cada vez mais espaço a enfoques voltados para o papel da agência e das relações entre os atores ${ }^{4}$. Distanciando-se

\footnotetext{
${ }^{4}$ Essas contribuições que se voltam para o papel da agência têm sido influenciadas, direta ou indiretamente, pelo pragmatismo e pela fenomenologia, notadamente pela concepção de hábito de John Dewey, que fundamenta os conceitos de sincretismo político (Berk e Galvan, 2009) e projetos criativos (Berk, Galvan e Hattan, 2013). As diferentes correntes do pragmatismo americano e a fenomenologia assinalam a importância de um olhar mais próximo à experiência dos atores. Se Dewey aponta para a relevância de estudar as práticas e a criatividade dos atores enquanto lidam com os diferentes problemas com os quais se deparam ao longo de suas vidas, Schutz desconfia das explicações estruturalistas para o comportamento humano e assinala que é apenas olhando para a forma pela qual as pessoas dão sentido a suas experiências no mundo que podemos compreender suas ações.
} 
da noção mais clássica de instituições como estruturas de regras, normas e procedimentos que constrangem as ações dos indivíduos, diferentes autores apontam para o fato de que essas regras e normas também podem ser vistas como recursos ou matéria-prima para a ação criativa dos indivíduos (Mahoney e Thelen, 2010; Abers e Keck, 2013). Em outras palavras, as pessoas não são reprodutoras passivas de normas e regras, mas estão constantemente experimentando, reinterpretando e readequando regras institucionais. Isso se deve não apenas ao fato de os indivíduos serem dotados de criatividade (Joas, 1996) e capacidade reflexiva (Giddens, 2009), mas também ao fato de que instituições são compostas por inúmeras regras e rotinas que podem ser interpretadas e aplicadas de formas diferentes (Mahoney e Thelen, 2010), além de serem renegociadas constantemente (Abers e Keck, 2013).

Olhar para como os atores interpretam regras e recursos em diferentes contextos - o que exige partir da premissa de que há reflexividade e capacidade crítica na atuação desses atores - tem sido uma estratégia interessante para estudar mudança institucional. Comparando diferentes contextos institucionais, Mahoney e Thelen (2010) explicam como características e propriedades das instituições favorecem a utilização estratégica de determinadas regras por parte dos agentes, o que pode levar a diferentes tipos de mudança institucional. Olhando para as estratégias dos atores, Berk e Galvan (2013) demonstram como, por meio de "projetos criativos", eles se baseiam em uma variedade de recursos culturais e institucionais para solucionar problemas práticos e que podem levar à mudança nas normas. A chave analítica para compreender a mudança institucional estaria na observação de como projetos criativos se relacionam. Isso seria possível retraçando os caminhos que as pessoas deixam quando respondem à criatividade umas das outras, por exemplo, alinhando, aprendendo ou reposicionando seu 
projeto. Em outras palavras, é relevante mapear que tipo de colagem ou agenciamento - entre os diferentes atores e seus projetos - está presente em momentos críticos e fundantes (Berk, Galvan e Hattam, 2013).

O conceito de agenciamento também vem ganhando espaço na sociologia a partir da influência do pragmatismo, mais especificamente a partir da teoria do ator rede (Latour, 2005; Law e Hassard, 1999). Essa corrente é influenciada pela obra de Deleuze e Guattari (1994), que propõe uma ruptura ontológica em relação à concepção de sociedade como algo estabilizado ou caracterizado por uma ordem seja ela na forma de estruturas de dominação ou na forma de um organismo com funções complementares (Dewsbury, 2011). Ao contrário, a sociedade (assim como todas as outras coisas) deveria ser concebida como resultado efêmero da agregação de diferentes elementos em determinado tempo e espaço (Marcus e Saka, 2006). O arranjo decorrente dessa 120 colagem é sempre instável, estando em constante processo de formação e reformulação. Nesse sentido, a ideia de agenciamento faz referência à composição resultante desse processo de montagem, variando sempre de acordo com os elementos que a compõem.

A agenda de pesquisa das correntes da teoria social influenciadas por esse giro ontológico tem se voltado para compreender os processos de colagem que levam ao surgimento e ao desaparecimento de determinados agenciamentos, bem como as relações entre os diferentes elementos que as compõem (Bennett, 2010). Todo agenciamento é composto por elementos materiais (recursos humanos, físicos, tecnológicos etc.) e expressivos (enunciados, linguagem, leis etc.) que são relevantes não por sua essência anterior à interação, mas pelas conexões que estabelecem entre si (De Landa, 2006; Srnicek, 2007; Latour, 2005).

$\mathrm{Na}$ esteira da ruptura ontológica que problematiza o social como algo estável, as correntes influenciadas pelo 
pós-estruturalismo de Deleuze e Guatarri buscam dar ênfase às condições sempre emergentes e instáveis do presente (Marcus e Saka, 2006). Com efeito, o conceito de agenciamento permite analisar esse processo dinâmico de construção do social por meio dos conceitos de territorialização e desterritorialização (Deleuze e Guatarri, 1994; De Landa, 2006). O primeiro diz respeito ao processo de estabilização de determinado arranjo a partir do aumento da homogeneidade entre os componentes internos ou a partir da definição de fronteiras externas. No âmbito institucional ou político isso ocorre, por exemplo, com a construção de um entendimento em torno de um conceito ou norma. Quanto mais estável é um agenciamento resultante desse processo de estabilização, mais territorializado ele é. A estabilização de controvérsias e disputas é fundamental para a construção daquilo que concebemos como instituições sociais (Latour, 2005; Boltanski e Thévenot, 1999). A desterritorialização seria o caminho inverso, caracterizado pela perda de homogeneidade de um agenciamento, ou por sua desestabilização. Um exemplo seria a perda de legitimidade paulatina de uma autoridade tradicional em uma sociedade racionalizada, em que as associações materiais e semióticas antes existentes estariam em processo de desestabilização (Srnicek, 2007).

A prevalência da ênfase na relação entre as partes (sejam elas projetos, organizações ou indivíduos) que constituem um arranjo, em detrimento do olhar para a agência de indivíduos específicos, também está presente na abordagem ecológica de Ansell (2013). Ao olhar para processos de mudança política e institucional, o autor se preocupa em não privilegiar a perspectiva de um único ator ou instituição na explicação, assinalando que os atores estão sempre embebidos em redes de atividades e enraizados em contextos específicos que moldam seu comportamento. Portanto, uma explicação deve sempre começar com a imagem dos atores 
inseridos no espaço e no tempo. Oportunidades locais para a criatividade situada são ligadas e alinhadas por atores e instituições que estão localizados de forma fortuita na ecologia, e isso pode levar à mudança institucional.

Em que pesem as variações entre as diferentes abordagens influenciadas pela noção relacional de agenciamento, cabe apontar que elas têm em comum a preocupação em mapear o processo de construção desses arranjos. A análise e a explicação do fenômeno que se deseja estudar se dão por meio desse mapeamento. Com efeito, para os autores identificados com o pragmatismo francês é recompondo as situações de controvérsia que se torna possível observar como o social é fabricado em cada contexto (Latour, 2005) e quais critérios de grandeza e de normalidade orientam a ação dos indivíduos (Boltanski, 1990). Reconstruir e descrever esse agenciamento é explicar como determinada realidade vem a ser da forma que é, quais atores e relações foram 122 determinantes para sua gênese e porque ela adquiriu seu formato atual. Da mesma maneira, Berk, Galvan e Hattam (2013) defendem que, para compreender como uma instituição muda, é necessário olhar para as relações entre os diferentes projetos criativos e sincréticos agenciados pelos atores em determinado contexto. A colagem possível entre eles pode levar a um agenciamento que implica mudança.

Os aportes que propõem o conceito de agenciamento como recurso heurístico e seu mapeamento como ferramenta metodológica podem contribuir para compreender como instituições mudam ao longo do tempo. No restante deste artigo discuto as mudanças pelas quais passou a política de reforma agrária no Brasil, desde a redemocratização até o início do governo Lula, com enfoque no papel do Incra. Mais especificamente, o objetivo é explicar como foi construído ao longo do tempo o formato atual de implementação de políticas, feito em parceria com os movimentos sociais. Traço a gênese do que defino como "relação de 
parceria" (Penna, 2015) entre Incra e movimentos sociais a partir das noções de sincretismo, criatividade política e agenciamento. Argumento que os momentos significativos de mudança na forma de implementação das políticas de reforma agrária são caracterizados por mudanças no agenciamento, que são visíveis pelas controvérsias e disputas engendradas no interior do órgão. A seguir descrevo cada um desses agenciamentos e controvérsias, buscando explicar como foram possíveis as mudanças institucionais ao longo do tempo.

\section{A gênese da relação de parceria entre Incra e movimentos sociais}

\section{Da colonização à reforma agrária}

A transição democrática é um marco para a redefinição das políticas de reforma agrária, assim como para outras esferas de políticas públicas. No caso das políticas fundiárias na região Norte do país, a volta à democracia significa a ruptura com os grandes investimentos dos governos militares em políticas de colonização. Os projetos de regularização fundiária e de colonização, por meio do assentamento dirigido e organizado de famílias de agricultores em regiões estratégicas (como às margens da rodovia Transamazônica), era prioritário do ponto de vista da segurança nacional; por isso recebia recursos significativos do governo militar ${ }^{5}$. O órgão implementador dessas políticas era o Incra, que havia sido criado em 1970 a partir da fusão de dois institutos ${ }^{6}$

\footnotetext{
${ }^{5}$ O governo militar estava destinando terras não apenas a trabalhadores rurais, mas também - e principalmente - para grandes produtores rurais e empresários do Sudeste, intensificando a concentração de terra na região e criando um contexto propício para o aumento do conflito entre posseiros pequenos e grandes (Hébette, 2004).

${ }^{6}$ Instituto Brasileiro de Reforma Agrária (Ibra) e Instituto Nacional de Desenvolvimento Agrário (Inda).
} 
existentes desde a promulgação do Estatuto da Terra ${ }^{7}$. Entre os anos 1970 e 1980 o Incra era um órgão de forte presença na região Norte, praticamente um Estado dentro do Estado (Velho, 1976), com poder e recursos significativos para levar a cabo o ordenamento fundiário oficial da região. Ainda que os resultados das políticas tenham sido ineficientes perante o montante de recursos investidos - haja vista o grande número de evasão e abandono das terras pelas famílias assentadas (Hébette, 2004) - o poder do Incra sobre a forma de ocupação da terra foi expressivo naquele contexto e segue presente na memória coletiva dos servidores mais antigos (Brasil, 2006).

O escritório regional de Marabá, que até 1980 era vinculado ao projeto fundiário de Belém, se torna a partir desse ano sede do Grupo Executivo de Terras do Araguaia e Tocantins (Getat). O grupamento foi criado devido ao aumento significativo no número de conflitos violentos 124 relacionados à posse da terra na região no final dos anos 1970. Como a área era considerada prioritária do ponto de vista estratégico, o governo militar criou o Getat, vinculado diretamente ao Conselho de Segurança Nacional da Presidência, com o objetivo de acelerar a regularização fundiária, acabando assim com o conflito. A consulta ao arquivo de Marabá revelou uma grande quantidade de títulos expedidos durante o Getat em comparação com o período anterior, do Projeto Integrado de Colonização (PIC), e com o período posterior, de Superintendência Regional do Incra.

A relação entre o Getat e os beneficiários das políticas fundiárias era muito diferente da atual relação entre o Incra e os assentados. Os servidores entrevistados relatam que naquela época não existia "essa coisa de movimento social e

\footnotetext{
7 Uma das primeiras leis sobre reforma agrária no Brasil, o Estatuto "regula os direitos e obrigações concernentes aos bens imóveis rurais, para os fins de execução da Reforma Agrária e promoção da Política Agrícola" (Lei nº 4.504, de 30 de novembro de 1964).
} 
de sindicato”. Qualquer tipo de organização ou ação coletiva era reprimida e "era tudo muito controlado". Eram os servidores do Getat que tinham o controle sobre o processo de regularização fundiária, que selecionavam famílias e as levavam até o local de assentamento. Em suma, a implementação da política fundiária naquele momento era caracterizada pelo protagonismo do Estado e pelo controle quase total da ocupação territorial. Os beneficiários, então denominados "colonos" ou "clientes", tinham pouco espaço de manobra e nenhum poder de barganha na definição de seu destino. Tampouco tinham organizações que representassem seus interesses, uma vez que os sindicatos de trabalhadores rurais existentes naquele período tinham atuação apenas formal e eram dirigidos por lideranças ligadas ao regime militar.

Os procedimentos, regras e práticas que caracterizavam a rotina burocrática dos servidores que implementavam as políticas fundiárias do Getat passam por uma mudança significativa a partir de 1985, com a redemocratização. Se antes eles estavam acostumados a solucionar problemas concretos fundamentados no poder e na autoridade da organização que representavam, com a redemocratização e a participação cada vez mais ativa de sindicatos e movimentos sociais, esses servidores precisam redefinir e readequar suas práticas ao novo contexto.

As mudanças institucionais que se deram no Incra com a redemocratização se devem não apenas à mudança de regime, tampouco podem ser consideradas reações automáticas ao novo contexto político. Uma reorientação nas práticas e regras do Incra a partir de 1985 se dá devido ao trabalho criativo de uma equipe nova que se depara com a necessidade de solucionar problemas concretos para viabilizar a implementação do novo PNRA, aprovado em 1985. O Plano estabelece como prioritária a política de reforma agrária por meio do assentamento de trabalhadores rurais, em lugar da antiga política de colonização, e define como 
necessária a participação dos beneficiários e de seus representantes no processo de implementação da política:

No Programa de Assentamento de Trabalhadores Rurais, a concepção do projeto técnico contará, em todos os níveis e fases, com uma participação direta dos beneficiários, em particular no que se refere às decisões sobre as formas possessórias e de uso da terra [...]. É imprescindível que seja estimulada e garantida a participação das diferentes instituições, sindicatos, associações, grupos e movimentos através de canais que a viabilizem democraticamente, objetivando constante interação com os trabalhadores assentados (Brasil, 1985, p. 14903).

Concomitantemente a essa mudança na legislação, uma equipe nova assume o Incra, dirigida pelo então ministro Nelson Ribeiro e composta por acadêmicos e militantes da questão agrária que haviam trabalhado na formulação do PNRA, tais como: José Gomes da Silva (presidente do Incra), Moacir Palmeira (diretor de Recursos Fundiários) e Alfredo Wagner de Almeida (chefe da Coordenadoria de Conflitos Agrários). Embora tenha durado apenas um ano, essa gestão deu os primeiros passos no sentido de mudar a forma como o Incra se relacionava com os movimentos sociais.

Ao chegar ao Incra, em 1985, Palmeira (1994) relata que se deparou com uma forte presença do lobby patronal, com advogados de grandes empresários e produtores rurais circulando livremente pela sede do órgão e com amplo acesso a servidores e arquivos. Trabalhadores rurais e seus representantes não tinham acesso equivalente, e sua presença era praticamente inexistente no Incra. Para reverter a assimetria de tratamento entre os diferentes públicos beneficiários das políticas fundiárias, Palmeira (1994) relata que sua equipe ampliou o acesso dos trabalhadores à sede 
nacional para neutralizar o forte lobby dos proprietários, já impregnado no cotidiano de trabalho do órgão:

Só ao abrirmos as portas do Incra aos trabalhadores é que esse quadro foi alterado. Inicialmente tímidos, limitando-se aos contatos com aqueles diretores e assessores que conheciam, os trabalhadores foram aos poucos descobrindo os meandros da burocracia e aprendendo a exercer sua pressão até sobre os escalões mais baixos. Então ocorreu um fenômeno curioso: se a presença de representantes dos proprietários não assustava, a visita de grupos de trabalhadores rurais, alheios aos mecanismos de conivência que associavam proprietários e burocratas e às regras "diplomáticas" da casa, causava medo. Com medo, os próprios funcionários vieram se queixar dessa nova presença. Quando isso aconteceu, tivemos condições de fazer que as regras de acesso a funcionários e a processos fossem efetivamente cumpridas e aplicadas a todos (Palmeira, 1994, p. 55).

Nesse caso é interessante notar como os gestores se utilizaram da criatividade, em face da necessidade de solucionar um problema prático, para tentar mudar regras e procedimentos tácitos que caracterizavam a rotina burocrática no Incra.

As práticas criativas utilizadas pela nova direção do Incra para garantir maior proximidade entre o órgão e os trabalhadores rurais foram diversas. Com a transição democrática cria-se uma incerteza quanto aos rumos da reforma agrária. A União Democrática Ruralista (UDR) se organiza formal e informalmente para lutar contra a reforma agrária e intensifica suas ações de intimidação e violência nas áreas rurais. Isso leva a um recrudescimento do conflito com as organizações de trabalhadores rurais e ao aumento no número de mortes violentas relacionadas à luta pela 
terra, notadamente na região de Marabá. Uma ação prática tomada pela Coordenadoria de Conflitos Agrários no Incra para lidar com esse problema imediato foi estabelecer uma linha telefônica, de funcionamento constate, para a qual as pessoas podiam ligar e denunciar conflitos agrários (Dias, 2009).

Outra ação prática emergencial para solucionar essa tensão foi proceder ao levantamento de todas as áreas de conflito social e agilizar a reforma agrária nessas áreas, que passaram a ser consideradas prioritárias para a desapropriação. No sul do Pará, com um dos maiores índices de conflito social, a definição dessas áreas foi feita por meio de reunião com representantes de trabalhadores rurais e posseiros. Em fevereiro de 1986, líderes de sindicatos e representantes da Comissão Pastoral da Terra (CPT) se reuniram com gestores e técnicos do Incra, na sede do órgão em Brasília, para definir áreas prioritárias e diretrizes para desapropriações na região. Todos os processos de desapropriação iniciados na década de 1980 e constantes no arquivo da Superintendência de Marabá fazem referência ao ofício resultante dessa reunião, reproduzido e citado nos processos ${ }^{8}$.

Essa solução prática para o problema da tensão social, que passa pela desapropriação de áreas prioritárias, altera o agenciamento até então existente no Incra. Se a definição de procedimentos para implementar políticas fundiárias era

\footnotetext{
8 "Ofício/CAC/MiRAD no 8 Brasília, 5 de fevereiro de 1986: Excelentíssimo Senhor Ministro, Nos dias 3, 4 e 5 de fevereiro foram realizados inúmeras reuniões de trabalho relativas aos conflitos de terra na região sudeste do Pará. Participaram destas reuniões cerca de 40 (quarenta) trabalhadores rurais dos Municípios de Marabá, Rio Maria, Conceição do Araguaia e São João do Araguaia. Participaram também representantes da Confederação Nacional dos Trabalhadores na Agricultura (CONTAG), da Comissão Pastoral da Terra do Araguaia-Tocantins, além de inúmeros técnicos deste Ministério vinculados aos seguintes órgãos: Diretoria de Recursos Fundiários (DF-Incra), Coordenadoria de Administração de Conflitos (SG-Mirad) e Unidade Executiva de Conceição do Araguaia (Getat) e Grupamento Fundiário (GF-Getat). A partir do exame detido de cada situação de conflito foram delineadas as seguintes medidas que ora apresentamos à apreciação superior de Vossa Excelência" (Brasil, 1986).
} 
prerrogativa apenas do Estado, a inclusão dos representantes de trabalhadores rurais na decisão sobre áreas prioritárias implica uma alteração na configuração de atores envolvidos no processo. Embora essa ação tenha sido bastante contestada, com forte resistência por parte de setores patronais e poderosos que tinham interesses nas áreas apontadas como prioritárias - e que eventualmente conseguiram impedir a desapropriação de algumas dessas áreas - a incorporação dos movimentos em decisões como essa foi uma prática que ganharia cada vez mais espaço no Incra.

As mudanças na direção do órgão em nível nacional eram acompanhadas por mudanças na regional de Marabá. Em 1985 o escritório continuava sendo a sede do Getat, que só iria desaparecer em 1987. Contudo, a partir de 1986 o órgão passa a ter um gestor civil, o advogado e especialista em direito agrário e fundiário Ronaldo Barata. Os pareceres e decisões assinados por esse gestor, e presentes no arquivo, demonstram uma postura favorável à negociação com os sindicatos. Contudo, isso não significa que a incorporação dos representantes dos trabalhadores rurais no processo de implementação tenha se dado de maneira automática no escritório regional. Com efeito, o retorno da democracia e o papel dos beneficiários e sindicatos na implementação da nova política de reforma agrária gerou inicialmente uma situação de incerteza para os servidores, que se adaptaram ao novo contexto a seu modo e tempo. Se o período militar era caracterizado por uma rotina burocrática na qual os servidores tinham maior autoridade e insulamento em relação aos beneficiários, com a redemocratização aprender a trabalhar em parceria com movimentos sociais passa paulatinamente a fazer parte dessa rotina.

É importante notar que a mudança de regime e a aprovação de um novo PNRA não foram suficientes para gerar uma mudança imediata nos procedimentos e normas tácitas que orientavam a implementação da política fundiária pelo 
Incra. Foi necessário o trabalho criativo de uma gestão engajada com a proposta de reforma agrária da nova democracia, que abriu espaço para a participação dos movimentos sociais no âmbito nacional, o que, por sua vez, foi alterando práticas e procedimentos burocráticos no nível local. A abertura de maior espaço para participação de movimentos sociais deve ser compreendida também em um contexto de crescente organização e ação de sindicatos e desses movimentos. Como veremos a seguir, a mudança no agenciamento que caracterizava a política fundiária no período militar é tributária, em grande medida, da capacidade organizativa e de pressão do movimento social a partir do final dos anos 1980. Não estivessem os sindicatos organizados e pressionando o governo por reconhecimento como representantes legítimos, não teria sido possível sua inclusão na mesa de negociações quando da transição democrática.

O primeiro passo em direção à incorporação dos representantes dos trabalhadores rurais nas decisões sobre política fundiária é dado em 1985. Contudo, o trajeto entre esse primeiro momento e a atual "relação de parceria" não é linear e sem percalços. A mudança no agenciamento da implementação de políticas de reforma agrária que inclui os movimentos sociais demoraria muitos anos para se consolidar, e ainda é alvo de controvérsia no Incra (Latour 2005; Boltanski, 1990).

Ainda em 1986 a gestão mais afinada com representantes dos trabalhadores rurais, e que tentara incorporá-los no processo de decisão, é substituída em um contexto de forte resistência e pressão por parte de grandes produtores rurais. A definição de áreas prioritárias para desapropriação a partir do critério de tensão social ${ }^{9}$ feriu interesses de setores poderosos e influentes, que tinham conexões políticas e

\footnotetext{
9 Tensão social fabricada pela presença de trabalhadores posseiros representados por sindicatos, como assinalam Sigaud (2005) e Rosa (2011).
} 
pressionaram o instituto para a saída da equipe de Nelson Ribeiro. A pressão se tornou insustentável e a gestão do Incra e do Ministério da Reforma e do Desenvolvimento Agrário (Mirad) foi substituída (Dias, 2009). Os processos de desapropriação das áreas prioritárias se prolongaram por muitos anos, alguns por mais de uma década, e muitas dessas grandes propriedades acabaram não sendo desapropriadas.

Contudo, a presença dos movimentos sociais no Incra, participando de forma associativa na formulação e na implementação de políticas, cresceu ao longo da década de 1990. Isso se deve, em grande medida, à organização e ao poder de mobilização dos movimentos. O Massacre de Eldorado dos Carajás, em 1996, é um marco nesse processo, com implicações para a relação entre Estado e movimentos sociais em todo o país, e no caso específico de Marabá teve efeitos concretos de mudança institucional.

\section{Massacre de Eldorado dos Carajás e criação da SR-27}

O escritório de Marabá, que, com o fim do Getat, volta a ser uma Unidade Avançada subordinada a Belém, muda novamente seu status em 1996, quando se torna uma Superintendência Regional (SR). A criação de uma Superintendência responsável pelo sul e sudeste do Pará, subordinada diretamente à sede da autarquia em Brasília, é uma resposta à demanda dos movimentos sociais na esteira do Massacre de Eldorado dos Carajás. O Massacre ocorre em um momento de crescimento e intensificação da luta do movimento social, aumentando ainda mais sua visibilidade (Ondetti, Wambergue, Afonso, 2010). Um de seus efeitos foi chamar a atenção para a gravidade do conflito agrário na região e para a necessidade de uma presença mais ativa do Estado. Após o Massacre o poder público se vê obrigado a atender algumas demandas dos movimentos sociais, e observa-se uma intensificação na política de criação de assentamentos. Isso leva ao aumento no número de acampamentos em todo o 
país, concomitantemente ao aumento na base dos movimentos rurais.

A intensificação da luta dos movimentos no sul do Pará no início dos anos 1990, que acaba por criar as condições que levaram ao Massacre, é resultado de um longo processo de organização social que vinha sendo construído desde o final do regime militar. No fim da década de 1970 a CPT começa um importante trabalho de assessoramento e de formação política de trabalhadores rurais na região, que posteriormente se tornam lideranças sindicais (Assis, 2009). Com o fim da repressão e no escopo do novo PNRA, os sindicatos começaram a atuar de forma mais institucionalizada e passam a ser vistos oficialmente como representantes dos interesses dos trabalhadores. A participação na reunião para definir as áreas prioritárias para desapropriação é um indicativo disso. Os processos de desapropriação consultados no arquivo de Marabá passam a contar, a partir de 1985, com ofícios assinados por sindicatos e documentos que evidenciam a troca de informações entre sindicatos e Incra.

Esse novo papel assumido pelas entidades representantes dos trabalhadores rurais implica uma transformação no agenciamento até então existente. Na nova configuração que caracteriza o processo de implementação de políticas pelo Incra, os sindicatos passam a ter algum grau de poder decisório e começam a ser vistos como interlocutores legítimos. Isso se deve mais à organização e pressão constantes exercidas pelas entidades sindicais do que à abertura automática e voluntária do Estado à sociedade civil no contexto da redemocratização. A pressão e organização dos movimentos teve efeitos não só na abertura de espaços de negociação, mas também na própria configuração institucional do Incra. A transformação do escritório de Marabá em uma Superintendência autônoma se deveu não a uma decisão de cima para baixo de gestores nacionais; foi antes o resultado 
direto da ação organizada e das reivindicações dos beneficiários das políticas de reforma agrária.

Logo após o Massacre, os movimentos começam a demandar maior presença do Estado, o que facilitaria o diálogo. O seguinte relato de um servidor ajuda a compreender o que ocorreu nesse momento:

Essa SR foi criada assim, meio no tapa. Aqui a gente era uma Unidade Avançada, era um grupo pequeno de funcionários comandado pela SR-01, Belém. Aí houve em 1996 uns conflitos com o MST e com os movimentos sociais em geral, e a partir daí foi uma exigência deles que o governo olhasse mais próximo aqui essa região de Marabá. Aí em 96 foi criada a SR-27 de Marabá, onde funciona até hoje. Então ela passou de uma Unidade para uma SR. Da mesma forma que ela foi criada assim no supetão, os funcionários foram obrigados a aprender a deixar de ser uma UA para ser uma SR. Ou seja, deixar de ser comandado para comandar. Isso é uma dificuldade muito grande, a pessoa mudar de, como diz, no caso, mudar de direção o navio sem ter comandante (Servidor de Marabá, no Incra desde 1977).

A criação da Superintendência a partir da pressão dos movimentos não garantiu automaticamente a eles espaço na mesa de negociações. Pelo contrário, eles continuaram organizando ações cada vez mais massivas para pressionar a SR por maior espaço nas decisões sobre a forma de implementação dos recursos destinados à região. Nos anos que se seguiram à criação da Superintendência os movimentos organizaram grandes acampamentos na porta do órgão, com milhares de pessoas e durante meses. A partir desses acampamentos e das negociações que se seguiram surgiram espaços de diálogo, e foram ficando mais claros os papéis do Incra e dos movimentos no processo de reforma agrária (Intini, 2004). Uma forma de cooperação, ainda que 
incipiente, caracterizada de um lado pela pressão e de outro pelo reconhecimento de certas atribuições aos movimentos, estava se estabelecendo nos anos 1990.

Nesse período se consolida um novo agenciamento no processo de implementação de políticas de reforma agrária. Os movimentos ganham cada vez mais espaço, influenciando inclusive o arranjo institucional do Incra quando da criação da Superintendência de Marabá. A pressão por meio da ação coletiva abre espaço para uma prática de cooperação informal, na qual o movimento tem a função de indicar a demanda. Esse novo agenciamento implica um aprendizado cotidiano por parte das lideranças dos movimentos, que começam a se familiarizar com a rotina burocrática, e também por parte dos servidores, que devem readequar constantemente as regras e os procedimentos que orientam seu trabalho. Em que pese a criatividade dos servidores que tiveram de reinventar suas práticas e rotinas perante a pre134 sença crescente dos movimentos, é importante notar que a mudança institucional pela qual passou o Incra na década de 1990 não é resultante apenas da criatividade política de gestores inseridos na organização burocrática. Nesse caso a gestão burocrática veio a reboque da inventividade dos potenciais beneficiários da política. A mudança institucional é tributária da ação dos movimentos sociais e das soluções criativas que eles encontraram para resolver seus problemas, notadamente o da falta de espaço para dialogar com o Estado.

A forma de cooperação consolidada nos anos 1990, que antecede a relação de parceria, é caracterizada ao mesmo tempo pelo reconhecimento dos movimentos como representantes legítimos dos beneficiários do Incra (Sigaud, 2005) e pela oposição entre projetos políticos (Dagnino, Olvera, Panfichi; 2006). O reconhecimento do papel do movimento de indicar a demanda está relacionado tanto à sua função histórica de organização dos trabalhadores do 
campo quanto à fragilidade do Incra em termos de recursos e de força de trabalho, haja vista o lugar marginal da reforma agrária na agenda de políticas públicas nas últimas décadas (Wolford, 2010).

Apesar do espaço conquistado pelos movimentos na definição das políticas de reforma agrária, a cooperação que se estabelece entre eles e o Incra antes de 2003 ainda não pode ser compreendida na chave da "parceria”. No nível programático há incompatibilidade de projetos políticos entre movimentos rurais e governo FHC. No nível prático os servidores do Estado ainda percebiam os movimentos com certo estranhamento. As lideranças não estavam cotidianamente dentro do órgão, participando presencialmente de negociações e deliberações. As narrativas dos servidores da década de 1990 são permeadas de histórias sobre a tensão com a ameaça constante de ocupação de seu local de trabalho e o medo de serem sequestrados e mantidos reféns no processo de negociação, na época em que "o movimento batia muito forte." A noção de movimentos sociais como "parceiros" do Incra aparece apenas no governo Lula, quando há uma mudança qualitativa na relação entre Estado e movimentos sociais.

De cooperação a parceria: a mudança com o governo do PT

A vitória do Partido dos Trabalhadores (PT) nas eleições de 2002 é um "momento de oportunidade" (Almeida, 2008) para diversos setores de movimentos sociais, dentre eles os ligados à luta pela reforma agrária. Assim como ocorreu em outras organizações estatais, militantes do partido e de organizações da sociedade civil assumiram cargos de gestão no Incra, tanto no nível nacional quanto no nível regional. A mudança no contexto político teve implicações para a relação entre movimentos e Estado no processo de implementação das políticas de reforma agrária. 
Logo no início do governo Lula é aprovado um novo PNRA, com metas ambiciosas para desapropriações de terra e assentamento de trabalhadores. Contudo, apesar das altas expectativas por parte dos movimentos sociais, ficou claro logo nos primeiros anos de governo que a agenda da reforma agrária não ganharia a centralidade esperada e que as metas não seriam cumpridas, como assinalou Santos, liderança nacional do MST, em entrevista concedida a mim (Santos, 2008), Todavia, gestores ligados ao partido e aos movimentos sociais ocupavam cargos no Estado e seguiam lutando, agora internamente, pela execução da agenda da reforma agrária. $\mathrm{O}$ trabalho desses gestores requereu alto grau de criatividade, uma vez que eles precisavam lidar simultaneamente com a pressão do movimento social e negociar como representantes do Estado - um Estado com recursos insuficientes e sem condições de cumprir promessas políticas.

136 Do ponto de vista da rotina burocrática do Incra, o ingresso dos novos gestores também levou a mudanças. A maioria dos servidores de carreira não tinha experiência de trabalho com superiores de perfil militante - que trouxeram para dentro do órgão novas relações com lideranças de movimentos sociais - e tiveram que aprender a trabalhar nesse novo contexto, novamente readequando suas práticas e rotinas, como veremos a seguir. Por fim, é importante lembrar que a política do governo Lula de recomposição da força de trabalho estatal, que havia sido sucateada nos governos anteriores, levou a uma mudança institucional de larga escala. A entrada massiva de servidores concursados em diferentes órgãos estatais a partir de 2004, não apenas no Incra, mas em todas as esferas da administração pública, teve impactos significativos no processo de criação de políticas públicas. Nos órgãos ligados à questão fundiária ingressaram, por meio de concurso público, alguns servidores que tinham carreira militante em movimentos sociais e em 
partidos políticos (Penna, 2015). Alguns desses servidores, efetivos e comissionados, assumiram cargos de direção a partir de 2004, e sua presença no Incra foi responsável por propiciar relações mais próximas com os movimentos sociais.

No caso de Marabá, a mudança de governo levou à entrada de uma superintendente que havia sido uma das fundadoras do PT na região e que tinha vínculos estreitos com os movimentos sociais. Uma de suas primeiras ações foi trazer as principais lideranças para uma grande reunião na sede do órgão, na qual os servidores responsáveis pelo planejamento apresentaram aos movimentos os recursos disponíveis, e os movimentos apresentaram a demanda de famílias acampadas e de propriedades que não estavam cumprindo sua função social e eram passíveis de desapropriação. Ao cabo dessa e de várias outras reuniões, Incra e movimentos fecharam um acordo com diretrizes e ações prioritárias para os próximos anos. Em um dos pontos acordados, a Superintendência deixaria de lado a inscrição de pleiteantes a beneficiários por correio - programa criado pelo governo FHC como forma de mitigar a participação dos movimentos na implementação, mas que nunca chegou a funcionar de fato - e adotaria como referência a indicação de famílias organizadas pelos movimentos.

O momento em que a mudança de governo e de superintendente impacta na rotina de trabalho é relembrado por este servidor, quando perguntado sobre como era a relação com os movimentos antes do governo Lula:

S: A relação da SR com os movimentos mudou muito. Antigamente era mais difícil, hoje está mais harmoniosa. Hoje já há uma integração dos movimentos. Toda vez que a gente vai fazer alguma coisa, a gente convoca, articula com os movimentos, chama os movimentos. Qualquer decisão eles tomam parte. Disse um presidente do Incra: os movimentos são nossos parceiros, não podemos deixar eles 
de fora, eles que lutam pela permanência do Incra - MST, Fetraf, Fetagri. A relação é boa, no momento eu vejo como boa em relação ao que era antes.

C: Você fala antes do governo Lula? Antes de 2003?

S: Antes do governo Lula. 2002 pra trás não era muito boa não; depois, com o Lula, melhorou. É luta política e tal. Eles confiaram muito no Lula. Aquela coisa, começaram, chegaram mais para conversar, falaram a mesma linguagem, mais fácil de conversar.

C: Isso facilitou o trabalho do Incra?

S: Isso facilitou, melhorou muito o trabalho do Incra. Tinha um momento que a gente não conversava com os movimentos, eles explodiam.... Facilitou demais. Antes eu tinha medo desse povo, ficava longe, pensar eles na minha sala... Hoje já é diferente, eles passam aqui, querem saber como estão as coisas, como é o planejamento; eu digo: "Vem comigo, eu explico tudo...". No tempo em que eu fiquei sequestrado aqui, foi quatro horas da manhã que me liberaram, fecharam a porta. Foi antes de 2003, faz tempo. [...] Em 2004 a pessoa que assumiu aqui era ligada a eles, foi chamando eles para conversar. Eu, como era aqui de dentro, ela me chamava. Na reunião que teve aqui no auditório tinha trezentas pessoas e eu tive que ficar lá em cima também. Eles foram me conhecendo [...] Aí fui começando a falar assim, né, aí foi bom. De lá pra cá eu converso com eles aqui e tal (Servidor de Marabá, no Incra desde 1976).

Essa fala expressa uma mudança na forma de identificar os movimentos sociais, passando de um contexto em que eles eram vistos como alheios ao Estado, com certo 
estranhamento, para um contexto em que sua presença no órgão passa a ser naturalizada. É a partir desse momento que a relação de cooperação, pautada até então pela pressão e caracterizada por uma incompatibilidade de projetos políticos entre movimentos e gestores do Estado, vai se transformando em uma relação de parceria. Isso não ocorre de forma automática. O lugar que o movimento passa a ocupar no novo agenciamento, caracterizado pelo reconhecimento de seu papel como indicador da demanda no processo de implementação das políticas de reforma agrária, não implica uma abertura imediata para seu acesso interno ao Incra. Tampouco significa que os servidores, ainda não acostumados com a presença de militantes em seu local de trabalho, passam imediatamente a concebê-los como parceiros. Como a fala anterior indica, a naturalização da parceria na rotina burocrática requereu, e ainda requer, trabalho e readequação de práticas e procedimentos antigos. Servidores e lideranças de movimentos precisaram aprender a se relacionar em novos termos e de forma mais próxima.

Ainda que com a mudança para o governo Lula tenha havido compartilhamento de projetos políticos entre movimentos e gestores no Estado (Dagnino, Olvera, Panfichi; 2006), a relação de parceria que então passa a existir não exclui as dimensões de conflito e pressão na forma de ação coletiva. Se quando da implementação há uma cooperação institucionalizada, cabendo aos movimentos apresentar ao Incra a demanda, nos momentos de luta por recurso os movimentos recorrem à pressão - o que geralmente envolve ocupar a Superintendência e organizar acampamento em seu entorno ${ }^{10}$. Contudo, essa pressão também deve ser entendida na chave da parceria, pois é ela que, no mais das

\footnotetext{
${ }^{10}$ A ocupação de propriedade como ritual necessário para a obtenção de terras da reforma agrária e para a existência dos movimentos sociais é a outra dimensão da pressão e ação coletiva, contudo pertence à linguagem pela qual os movimentos se comunicam com o Estado e são por ele reconhecidos (Sigaud, 2005).
} 
vezes, garante recursos federais ao Incra. Há uma dependência mútua entre política pública, autarquia e pressão dos movimentos sociais (Penna e Rosa, 2015). A fala a seguir ilustra essa dimensão dupla da parceria:

Em todas as reuniões com o sindicato eu sempre falo que nós precisamos nos organizar. Quer dizer, quando eu falo nós, estou colocando os trabalhadores e o Incra também. Porque nós somos parceiros. Ai do Incra se não fosse os trabalhadores; não tinha Incra, né? Por isso nós nos tornamos parceiros. Claro que quando chega aquele momento que os nossos parceiros, que são vocês, têm que brigar com o Incra, vão brigar. Vão acampar, como acamparam ano passado em Marabá. E conseguiram até recursos que naquele momento não existiam, como conseguiram também balançar Brasília para que o Incra pudesse comprar duzentas viaturas (Servidor de Tucuruí, no $140 \quad$ Incra desde 1983).

A mudança institucional pela qual passou o Incra a partir de 2003, e que culmina na construção de uma relação de parceria entre Estado e movimentos sociais, não foi experimentada por todos os servidores da mesma forma. Ao passo que alguns servidores aprenderam a trabalhar em colaboração direta com lideranças de movimentos sociais, outros não concordam com o papel do movimento no processo de implementação e acreditam que deveria ser prerrogativa exclusiva do Incra a seleção de beneficiários e sua condução ao assentamento, uma vez desapropriada a terra. Essa posição é mais comum entre servidores antigos, que vivenciaram o período do Getat, mas não é exclusiva deles. Algumas pessoas que ingressaram no Incra após 2004 também defendem essa posição e argumentam que ela seria a mais correta, considerando os critérios técnicos que deveriam pautar a atuação da autarquia. 
O tema da parceria e do espaço reconhecido aos movimentos sociais no processo de implementação está no centro de uma controvérsia pública na Superintendência de Marabá (Thévenot e Boltanski, 1999; Penna, 2017). Os dois critérios de grandeza (Boltanski, 1990) que animam essa controvérsia são a defesa do valor da técnica no serviço público, acima de qualquer critério político, e o importante papel do movimento social de organização da demanda por reforma agrária, sem o qual o trabalho do Incra seria inviável, haja vista sua fragilidade em termos de recurso e mão de obra.

No centro dessa controvérsia está também a atuação dos gestores militantes, cuja posição no novo agenciamento requeria saídas criativas para problemas novos. Enquanto estive na regional de Marabá três militantes ocupavam importantes cargos comissionados de direção e recebiam lideranças de movimentos sociais cotidianamente. Contudo, a maior presença de lideranças no Incra a partir da mediação desses servidores nem sempre resultava em acordos ou consensos. Em diferentes reuniões que presenciei cabia a esses gestores comunicar aos movimentos que os acordos feitos em negociações anteriores não seriam cumpridos por falta de recursos vindos de Brasília. Cabia também a eles colocar limites às iniciativas dos movimentos quando estas ultrapassavam a barreira das funções do Estado. Em todos esses momentos o diálogo não era fácil, e em alguns casos as lideranças questionavam onde estava, de fato, a lealdade do gestor: se com o Estado ou com os trabalhadores rurais. Isso demonstra que, não obstante a trajetória dos gestores e o compartilhamento de projetos políticos, ocupar uma posição no Estado ou fora dele representa uma fronteira e um distanciamento significativo - haja vista a própria necessidade de mediação (Neves, 2008).

A criatividade desses servidores híbridos é necessária não somente para mediar a relação com os movimentos. 
Quando era necessário emitir ordens para os servidores subordinados havia sempre algum grau de contestação de sua legitimidade para tal - publicamente, quando havia espaço, ou de forma mais privada, como em uma entrevista. $\mathrm{O}$ questionamento da legitimidade desses chefes passava novamente pelo debate entre técnica e política, e sua atuação era julgada por seu caráter mais ou menos político. Lidar com esse questionamento e, em alguns casos, com a insubordinação requeria desses gestores uma atuação pautada pela criatividade. Entre os resultados dessa ação criativa, que buscou alinhar a possibilidade de comando e controle na hierarquia burocrática com a proximidade e confiança dos movimentos sociais, estão a abertura de espaço para os movimentos no Incra e o aumento da transparência, mesmo em um contexto inicial de resistência interna. Esse espaço foi fundamental para que os representantes dos trabalhadores rurais aprendessem a navegar pelos meandros da burocracia 142 e para que os servidores se habituassem a sua presença cotidiana - ambos fundamentais para a consolidação da relação de parceria que atualmente caracteriza o agenciamento da implementação de políticas na Superintendência.

\section{Conclusões}

Este artigo buscou traçar a gênese da atual relação de parceria entre Incra e movimentos sociais que caracteriza a implementação de políticas de reforma agrária na Superintendência de Marabá. Essa parceria, que envolve uma dimensão de pressão e uma de cooperação, é resultado de um longo processo de mudança institucional que se deu no Incra entre a redemocratização e o início do governo Lula. Nesse período, diferentes atores envolvidos com a reforma agrária - especialmente gestores públicos, servidores e movimentos sociais - se relacionaram de diversas formas, criando tipos diferentes de agenciamento que levaram a mudanças nas rotinas burocráticas e no trabalho do 
Incra. Passou-se de um arranjo no qual o órgão exercia suas funções de forma relativamente insulada dos beneficiários, para um no qual o trabalho da autarquia é caracterizado pela proximidade e cooperação direta com os movimentos sociais.

Três eventos históricos foram chave para as mudanças que estiveram na gênese dessa parceria: o retorno da democracia, o Massacre de Eldorado dos Carajás e a eleição de Lula para presidente em 2002. Esses acontecimentos estiveram na origem de processos de reorganização das relações entre os atores envolvidos com a reforma agrária, levando à desterritorialização de agenciamentos anteriores. Contudo, não são suficientes para compreender as mudanças institucionais que se seguiram e, por si só, não explicam o formato associativo assumido na esfera da implementação de políticas pelo Incra. Com efeito, a reorganização das relações entre Estado e movimentos após cada um desses eventos foi fruto da combinação das condições criadas por cada um deles e das estratégias criativas de diferentes atores envolvidos no processo de implementação da política.

Ao longo do artigo mostrei como esses três macroeventos na política nacional estiveram relacionados a mudanças no arranjo institucional no nível da Superintendência local e, consequentemente, à forma de implementação da política pública. É possível concluir que não há linearidade ou uma relação automática entre mudanças de orientação política no nível nacional e alterações nas formas de implementação de políticas em nível local. Como foi aqui demonstrado, as mudanças no processo de implementação de políticas de reforma agrária em Marabá implicaram trabalho e criatividade por parte dos diferentes atores envolvidos. Esse trabalho criativo teve como resultado a estabilização de agenciamentos que foram paulatinamente aproximando Estado e representantes dos trabalhadores rurais como parceiros. 
Os projetos criativos (Berk, Galvan e Hattam, 2013) dos gestores do Incra na nova democracia, concomitantemente à crescente organização do movimento sindical rural e à promulgação do novo PNRA, possibilitaram maior acesso dos trabalhadores rurais ao Estado e significaram o primeiro passo de uma mudança no agenciamento que havia sido estabilizado ao longo do regime militar, caracterizado por relações privilegiadas entre grandes proprietários rurais e Incra.

Após o Massacre de Eldorado dos Carajás, gestores públicos e lideranças de movimentos sociais agiram com criatividade para buscar uma solução para o conflito agrário. A mudança no arranjo institucional, cristalizada na criação da Superintendência após pressão dos movimentos, abriu espaço para a participação destes. Com maior capacidade organizativa e conhecimento técnico, os movimentos sociais foram adquirindo protagonismo, e aos poucos se estabele144 ceu uma relação de cooperação como agenciamento característico do processo de implementação de políticas - ainda que instável e marcada por pressão e conflito. Todavia, pode-se dizer que esse agenciamento cooperativo, no qual cabia aos movimentos apresentar a demanda de acampados, se territorializou ao longo dos anos 1990.

Com a transição para o governo do PT abre-se uma janela de oportunidades para o movimento social. Para que os impactos da mudança de governo no nível nacional atingissem o nível local - no que tange à relação com os movimentos sociais - foi necessário trabalho e criatividade de gestores híbridos. Esse trabalho está inserido em um campo de disputas (Latour, 2005; Boltanski e Thévenot, 1999), cujo mapeamento é fundamental para compreender o agenciamento característico da atual "relação de parceria". Nela, Estado e movimentos têm papéis distintos e complementares, sendo compreendidos como parceiros na implementação de políticas de reforma agrária. Esse arranjo é instável 
e caracterizado por uma disputa permanente em torno das fronteiras que definem o que é função do Estado e o que é função do movimento social. Com o impedimento da presidente Dilma em 2016, e com as implicações disso para a reorganização das elites políticas em todo o país, pode-se dizer que o agenciamento da parceria passa por um processo progressivo de desterritorialização ou desestabilização.

A gênese da relação entre Incra e movimentos sociais na implementação de políticas de reforma agrária ao longo das últimas décadas mostrou que é necessário um olhar ecológico (Ansell, 2013) para as relações entre os diferentes atores em cada momento, a fim de compreender o processo de mudança institucional. Para tanto, a noção de agenciamento como diferentes composições de relações que vão sendo estabilizadas e desestabilizadas ao longo do tempo se mostrou particularmente útil, notadamente para explicar um processo social que está constantemente em disputa e reorganização, como a relação entre movimentos rurais e Estado no momento da implementação de políticas públicas.

A mudança institucional gradual que caracteriza a transição de uma política de reforma agrária de caráter insulado para uma de parceria, ao longo das três últimas décadas, pode ser pensada como resultado de processos recorrentes de interpretação e aplicação criativa de regras em momentos de oportunidade distintos (Mahoney e Thelen, 2010). Os agenciamentos resultantes da combinação entre eventos externos e projetos e soluções criativas formuladas por diferentes atores mostram como o Estado vai se construindo e se estabilizando nas situações de interface entre orientações e normas gerais e ações práticas de atores que interpretam e dão vida a essas regras. 


\section{Camila Penna}

é professora do Departamento de Sociologia da Universidade Federal do Rio Grande do Sul (UFRGS), Porto Alegre, RS, Brasil.

\section{Bibliografia}

ABERS, Rebecca Neaera; KECK, Margaret Elizabeth. 2013. Practical authority: agency and institutional change in Brazilian water politics. Oxford: Oxford University Press.

ALMEIDA, Alfredo Wagner Berno. 2008. Terras de quilombo, terras indígenas, "babaçuais livres", "castanhais do povo", faxinais e fundos de pasto: terras tradicionalmente ocupadas. Manaus: Ufam.

ANSELL, Chris. 2013. Ecological explanation. In: BERK, Gerald; GALVAN, Dennis Charles; HATTAM, Victoria (Ed.). Political creativity: reconfiguring order and change. Philadelphia: University of Philadelphia Press, pp. 55-77.

ASSIS, William Santos. 2009. Mobilização camponesa no sudeste paraense e luta pela reforma agrária. In: FERNANDES, Bernardo Mançano; MEDEIROS, Leonilde Sérvolo; PAULILO, Maria Ignez (orgs.). Lutas camponesas contemporâneas: condições, dilemas e conquistas. São Paulo: Editora Unesp, v. 2, pp. 113-138.

BENNETT, Jane. 2010. Vibrant matter: a political ecology of things. Dunham: Duke University Press.

BERK, Gerald; GALVAN, Dennis Charles. 2009. How people experience and change institutions: a field guide to creative syncretism. Theory and Society, v. 38, n. 6, pp. 543-580.

2013. Processes of creative syncretism: experiential origins of institutional order and change. In: BERK, Gerald; GALVAN, Dennis Charles; HATTAM, Victoria (ed.). Political creativity: reconfiguring order and change. Philadelphia: University of Philadelphia Press, pp. 29-54.

BERK, Gerald; GALVAN, Dennis Charles; HATTAM, Victoria (Ed.). 2013. Political creativity: reconfiguring order and change. Philadelphia: University of Philadelphia Press.

BOLTANSKI, Luc. 1990. L'amour et la justice comme compétences: trois essais de sociologie del'action. Paris: Métailié.

BOLTANSKI, Luc; THÉVENOT, Laurent. 1999. The sociology of critical capacity. European Journal of Social Theory, v. 2, n. 3, pp. 359-377.

BRASIL. 1964. Lei no 4.504, de 30 novembro de 1964. Dispõe sobre o Estatuto da Terra e dá outras providências. Diário Oficial da União, Poder Legislativo, Rio de Janeiro, 30 nov. 1964. Seção 1, p. 49. Suplemento. 
1985. Decreto $n^{\circ} 91.766$, de 10 de outubro de 1985. Aprova o Plano Nacional de Reforma Agrária (PNRA), e dá outras providências. Diário Oficial da União, Poder Legislativo, Brasília, DF, 11 out. 1985. Seção 1, p. 14903.

- Instituto Nacional de Colonização e Reforma Agrária. Superintendência Regional do Pará. Grupo Executivo das Terras do Araguaia e Tocantins. 1986. Processo Fazenda Água Fria (Getat nº 027/86). Marabá: Incra SR 27.

Ministério do Desenvolvimento Agrário. 2006. Memória Incra 35 anos. Brasília, DF: Nead.

DAGNINO, Evelina; OLVERA, Alberto Rivera; PANFICHI, Aldo (orgs.). 2006. A disputa pela construção democrática na América Latina. São Paulo: Paz e Terra; Campinas: Editora Unicamp.

DE LANDA, Manuel. 2006. A new philosophy of society: assemblage theory and social complexity. London; New York: Continuum.

DELEUZE, Gilles; GUATTARI, Félix. 1994. Mil platôs: capitalismo e esquizofrenia. São Paulo: Editora 34, v. 4.

DEWSBURY, John-David. 2011. The Deleuze-Guattarian assemblage: plastic habits. Area, v. 43, n. 2, pp. 148-153.

DIAS, Guilherme Mansur. 2009. Entrevista: Alfredo Wagner Berno de Almeida. Ruris, v. 3, n. 2, pp. 17-54.

GIDDENS, Anthony. 2009. A constituição da sociedade. 3. ed. São Paulo: WMF Martins Fontes.

HÉBETTE, Jean. 2004. Cruzando a fronteira: 30 anos de estudos do campesinato na Amazônia. Belém: Edufpa, v. 4.

INTINI, João Marcelo. 2004. Luzes e sombras: negociação e diálogo no sul e sudeste do estado do Pará: um estudo sobre as políticas públicas para reforma agrária e agricultura familiar. 212 f. Dissertação de Mestrado em Agriculturas Familiares e Desenvolvimento Sustentável. Belém: UFPA.

JOAS, Hans. 1996. Intelligence and reconstruction: the creativity of action. Chicago: University of Chicago Press.

LATOUR, Bruno. 2005. Reassembling the social: an introduction to actornetwork-theory. Oxford: Oxford University Press.

LAW, John; HASSARD, John. 1999. Actor network theory and after. Oxford: Wiley-Blackwell.

MAHONEY, James; THELEN, Kathleen Ann. 2010.Explaining institutional change: ambiguity, agency, and power. Cambridge, UK: Cambridge University Press.

MARCUS, George Emanuel; SAKA, Erkan. 2006. Assemblage. Theory, Culture E' Society, v. 23, n. 2-3, pp. 101-106. 
NEVES, Delma Peçanha (org.). 2008. Desenvolvimento social e mediadores políticos. Porto Alegre: Editora UFRGS.

ONDETTI, Gabriel; WAMBERGUE, Emmanuel; AFONSO, José Batista. 2010. De posseiro a sem-terra: o impacto da luta pela terra do MST no Pará. In: CARTER, Miguel (org.). Combatendo a desigualdade social: o MST e a reforma agrária no Brasil. São Paulo: Editora Unesp, pp. 257-284.

PALMEIRA, Moacir. 1994. Burocracia, política e reforma agrária. In: MEDEIROS, Leonilde Sérvolo et al. (orgs.). Assentamentos rurais: uma visão multidisciplinar. São Paulo: Editora Unesp, pp. 49-69.

PENNA, Camila. 2015. Conexões e controvérsias no Incra de Marabá: o Estado como um ator heterogêneo. Rio de Janeiro: Garamond. 2017. Activism inside and outside the State: agrarian reform activists and bureaucrats in the state of Pará, Brazil. Revue Internationale des Études du Développement, v. 230, n. 2, pp. 103-125.

PENNA, Camila; ROSA, Marcelo Carvalho. 2015. Estado, movimentos e reforma agrária no Brasil: reflexões a partir do Incra. Lua Nova, n. 95, pp. 57-86.

ROSA, Marcelo Carvalho. 2011. O engenho dos movimentos: reforma agrária e significação social na zona canavieira de Pernambuco. Rio de Janeiro: Garamond.

148 SANTOS, M. Marina dos Santos. 2008. Depoimento [dez. 2008]. Entrevistadora: Penna, Camila. Brasília, DF: MST.

SIGAUD, Lygia. 2005. As condições de possibilidade das ocupações de terra. Tempo Social, v. 17, n. 1, pp. 255-280.

SRNICEK, Nick. 2007. Assemblage theory, complexity and contentious politics: the political ontology of Gilles Deleuze. $130 \mathrm{f}$. Dissertação de Mestrado em Ciências Sociais. Ontario: University of Western Ontario.

VELHO, Otávio Guilherme. 1976. Capitalismo autoritário e campesinato: um estudo comparativo a partir da fronteira em movimento. Rio de Janeiro: Difel.

WOLFORD, Wendy. 2010. Participatory democracy by default: land reform, social movements and the state in Brazil. The Journal of Peasant Studies, v. 37, n. 1, pp. 91-109. 


\section{D)}

\section{A GÊNESE DA RELAÇÃO DE PARCERIA ENTRE INCRA E MOVIMENTOS SOCIAIS COMO MODELO PARA IMPLEMENTAÇÃO DE POLÍTICAS DE REFORMA AGRÁRIA}

CAMILA PENNA

Resumo: $\mathrm{O}$ artigo tem o objetivo de explicar como o atual formato de parceria que caracteriza a implementação de políticas de reforma agrária pelo Instituto Nacional de Colonização e Reforma Agrária se construiu ao longo do tempo. Propondo um diálogo entre a literatura mais recente sobre mudança institucional e a literatura que trabalha a partir da noção de agenciamento (assemblage) para compreender processos políticos, analiso três momentos-chave de rearranjo das relações entre movimentos sociais e Estado: a redemocratização, o massacre de Eldorado dos Carajás e a transição para o governo Lula. Concluo que a gênese da atual relação de parceria é resultado de um processo gradual de estabilização de diferentes agenciamentos que combinaram macroeventos no nível nacional com projetos criativos de diferentes atores para resolver problemas locais.

Palavras-chave: Incra, movimentos sociais, reforma agrária, agenciamento, mudança institucional.

\section{THE GENESIS OF THE PARTNERSHIP BETWEEN INCRA AND SOCIAL MOVEMENTS AS A MODEL FOR AGRARIAN REFORM POLICIES IMPLEMENTATION}

Abstract: This article aims at explaining how the current format of partnership that characterizes the implementation of agrarian reform policies by Incra has been built over time. Proposing a dialogue between the most recent literature on institutional change and the literature on assemblage, I analyze three key moments in the rearrangement of relations between social movements and the State: democratization, the massacre of Eldorado dos Carajás, and the 
transition to the Lula government. I conclude that the genesis of the current partnership results from a gradual process of stabilization of different assemblages that combined macro events at the national level with creative projects of different actors to solve local problems. Keywords: Incra, social movements, agrarian reform, assemblage, institutional change

Recebido: $11 / 06 / 18 \quad$ Aprovado: 09/10/18 